\title{
Deposits Effects on Catalysts Porous Structure and Chemical Activity during Residuum Catalytic Hydro-treatment
}

\author{
Jamal Mohammad Amous \\ Chemical Engineering Department, Faculty of Engineering, University of Hail, Hail, Kingdom of Saudi Arabia
}

Copyright $\bigcirc 2018$ by authors, all rights reserved. Authors agree that this article remains permanently open access under the terms of the Creative Commons Attribution License 4.0 International License

\begin{abstract}
Catalyst Porous structure parameters and activity were investigated during the catalytic hydro-treatment of Heavy Arabian Oil atmospheric residuum utilizing a fixed bed catalytic reactor with recycle. Two model Hydro-treating catalysts CAT-1 containing $0.5 \mathrm{wt} \%$ Molecular Sieves (MS) 13X, and CAT-2, having different physical and chemical properties were used in this investigation. Spent, extracted and dried, catalyst samples were analyzed for their physical features and chemical deposits for both types, CAT-1 and CAT-2, with sizes having $\left(\mathrm{Lp}_{\mathrm{o}}\right)=0.059 \mathrm{~mm}$ and $\overline{L p}_{1}=0.326 \mathrm{~mm}$. It was found that carbonaceous deposits on CAT-1, $\overline{L p}_{0}=0$. $059 \mathrm{~mm}$ approached $41.91 \mathrm{wt} \%$ (S, C, H and N) g/100 g regen. Cat. The porous structure parameters were affected by the deposited materials. Surface areas lost due to deposits were in the range of 45 to $55 \%$ and pore volumes decrease was in the range of 43 to $52 \%$ compared with the fresh samples. Probable pore diameters decreased from around $80 \AA$ to $43 \AA$. Pores in the range between 105 to $165 \AA$ disappeared Especially in CAT-1 samples. Coke content of $\mathrm{S}, \mathrm{C}, \mathrm{H}$, and $\mathrm{N}$ with respect to the weight of the regenerated catalyst was around 4.0, 34.0, 1.9 and 0.50 wt. \% respectively. Vanadium (V) and Nickle (Ni) contents were in the range 0.63 and 0.27 wt. \% respectively. Extracted and dried spent catalysts samples were oxidized with dry air stream at $380^{\circ} \mathrm{C}$. Upon regeneration the carbonaceous deposits were removed and the porous structure parameters were recovered up to levels approaching $79-89 \%$ of those recorded for the fresh samples, depending on their sizes.
\end{abstract}

Keywords Catalyst, Pore Structure, Deposits, Regeneration, Residuum, Metals

\section{Introduction}

It has been suggested that the operating catalyst behavior is drastically affected by the physicochemical properties of the treated oil feedstock and the catalyst characteristics $[1,2]$. The analysis of used catalysts led to that the activity loss is attributed to carbonaceous and metallic deposits altering the chemically active surface and the physical structure of the employed catalyst $[3,4]$. The contribution of these factors depends on the reaction conditions, the origin of the feed stocks, the desired degree of Hydro-treatment and finally on the catalyst physicochemical features $[5,6]$.

\subsection{Coke Deposition and Properties}

Coke deposition within the catalyst structure is one of the factors imposing intra-particle diffusion limitations to both reactant and product molecules either by partial or complete pore plugging mechanism [7]. Furthermore, coke containing $\mathrm{N}-\mathrm{O}$ heteroatoms affect catalyst activity poisoning acidic active sites[8,9].It is also accepted that coke develops from reactive, unstable hydrocarbon species (coke precursors) with small or large molecular sizes( resins, heterocyclic compounds and Asphaltenes) $[10,11,12]$.

\subsection{Metal Deposits}

At the time where the effect of coke deposits is limited to reversible modifications of the pore structure, the effect of metallic deposits is responsible for the permanent alteration of the physical and chemical characteristics and are considered as the most critical factors determining catalyst life self , because they are irreversibly adsorbed on the catalyst active surface.

A controlled oxidation of spent catalysts can remove the deposited carbonaceous materials. Nickle and Vanadium are the most important metallic elements that affect catalyst activity and are frequently present in petroleum crudes. Porphyrins, Asphaltenes and Resins are 
believed to be the main source of metallic sulfides deposited on the operating catalysts $[1,3,11]$.

\subsection{Chemical Behavior of Catalysts during Oil Hydro-Treatment}

It is believed that the stable and active catalyst species are the sulfided metals i.e. $\mathrm{Mo}_{\mathrm{x}} \mathrm{S}_{\mathrm{y} \text { and }} \mathrm{Co}_{\mathrm{z}} \mathrm{S}_{\mathrm{d}}$, As it is impossible to get reliable composition data on operating industrial catalysts in situ, it was mentioned that for oxidic precursors treated with $\left(\mathrm{H}_{2} / \mathrm{H}_{2} \mathrm{~S}\right)$ at $400^{\circ} \mathrm{C}$ the degree of sulfudation was $95 \%$, with $(\mathrm{S} / \mathrm{Mo})$ atomic ratio approaching 2.44 , and $(\mathrm{S} / \mathrm{Co})$ atomic ratio around 0.63 [13].

\subsection{Quantitative Determination of Coke Deposited on Hydro Treating Catalysts}

The evaluation of the real effect of the carbonaceous materials upon the pore structure and the intrinsic chemical activity of the active catalyst phase (in situ) requires a standard method of coke and metal determination. Ammus [3] concluded that there is no standard method for quantitative determination of coke. Operating Hydro-treating catalysts on discharge they may contain unreacted oil, oil products, intermediate compounds, coke and metallic deposits mainly $\mathrm{V}$ and $\mathrm{Ni}$. Deactivation of catalysts and selectivity alteration can be attributed to coke and metal deposits plugging pores containing active surface area.

Reliable determination of coke requires de-oiling of the (as discharged) used catalysts to remove oily substance and an accurate determination of the metal deposits. It was suggested by Ammus and Androutsopoulous [6], that the most effective and useful method of de-oiling is the benzene extraction. Coke evaluated by subtracting the weight of the oxidized catalyst from the extracted and dried used catalyst is erroneous, because coke evaluations must contain a correction factor for the conversion of sulfides to the oxides of the active constituents. Thus coke must be expressed per mass of sulfide form of catalyst and sulfide metal deposits. The suggested form of coke and metal deposits bears a physical significance and is based on the assumption that both complete sulfidation and oxidation of the respective catalyst had occurred, so a reduced error is anticipated.

\section{Experimental}

Two model catalyst CAT -1 and CAT -2 with different physical and chemical features [Table 1] were investigated by Amous [14], applying Particles with different characteristic lengths $\overline{L p}_{0}=0.059 \mathrm{~mm}$ and $\overline{L p}_{1}=$ $0.326 \mathrm{~mm}$. The properties of the feedstocks being Hydro-treated are depicted in Table 2 [14]. CAT-1 with $\overline{L p}_{0}=0.059 \mathrm{~mm}$ containing $0.5 \mathrm{wt} . \%$ ( MS $13 \mathrm{X}$ ) is utilized in a plug flow reactor operating with high recycle ratio (complete back mixing at) $350^{\circ} \mathrm{C}, 50 \mathrm{~atm}$. and a LHSV of $2.6 \mathrm{~h}^{-1}$.

Table 1. Fresh catalysts chemical composition and main pore structure specifications.

\begin{tabular}{|c|c|c|}
\hline Cat.symb. & CAT- 1 & CAT- 2 \\
\hline$\gamma-\mathrm{Al}_{2} \mathrm{O}_{3}, \mathrm{Wt} \%$ & 85.9 & 86.4 \\
\hline $\mathrm{CoO}, \mathrm{wt} \%$ & 3 & 3 \\
\hline $\mathrm{MoO}_{3}, \mathrm{wt} \%$ & 10.6 & 10.6 \\
\hline $\mathrm{MS} 13 \mathrm{X}, \mathrm{wt} \%$ & 0.5 & 0 \\
\hline $\mathrm{Sg}, \mathrm{m} 2 / \mathrm{g}[\mathrm{BET}]$ & 188 & 181 \\
\hline $\mathrm{Sg}, \mathrm{m} 2 / \mathrm{g}[\mathrm{MP}]$ & 114 & 111 \\
\hline $\mathrm{Vp}(1)$ & 0.41 & 0.39 \\
\hline $\mathrm{Vp}(2)$ & 0.32 & 0.34 \\
\hline $\mathrm{dp}(1)$ & 83 & 87 \\
\hline $\mathrm{dp}(2)$ & 123 & 128 \\
\hline$\rho \operatorname{\rho obs} . \mathrm{bed}, \mathrm{g} / \mathrm{cm} 3$ & 0.78 & 0.75 \\
\hline
\end{tabular}

Sg: Specific Surface Area / BET. [m2/g], M.P**: Mercury Penetration(1800 bar), $\mathrm{Vp}^{(1)}$ : Pore volume measured with $\mathrm{N}_{2}$ Ads-Des technique, $\mathrm{Vp}^{(2)}$ : Pore volume measured with mercury penetration, $\mathrm{dp}^{(1)}$ : Most probable pore diameter in Angstrom( $\AA$ )measured with $\mathrm{N}_{2}$ Ads-Des., $\mathrm{dp}^{(2)}$ : Most probable pore diameter in $\operatorname{Angstrom}(\AA)$ measured with mercury penetration technique. $\rho_{\text {obs.bed }}$ observed bed density $\mathrm{g} / \mathrm{cm}^{3}$.

Table 2. Properties of Treated Heavy Oil Residuum

\begin{tabular}{|c|c|}
\hline Property & Value \\
\hline Boiling point,${ }^{\circ} \mathrm{C}$ & $>330^{\circ} \mathrm{C}$ \\
\hline API & 9.0 \\
\hline $\mathrm{S}, \% \mathrm{wt}$ & 4.65 \\
\hline $\mathrm{V}+\mathrm{Ni}, \mathrm{ppm}$ & 132 \\
\hline Carbon residue, $\% \mathrm{wt}$ & 13.62 \\
\hline Sp. gravity, $15 / 4{ }^{\circ} \mathrm{C}, \mathrm{g} / \mathrm{cm}^{3}$ & 1.007 \\
\hline Kinematic viscosity, $122^{\circ} \mathrm{F}, \mathrm{cSt}$ & 229 \\
\hline
\end{tabular}

Porous structure parameters are measured applying the $\mathrm{N}_{2}$ adsorption-desorption and Mercury penetration techniques and specific surface areas, pore volumes and pores diameters and pore size distributions were deduced for fresh, spent and regenerated catalyst samples.

Catalyst activity is investigated as a function of catalyst age. The reactor operating 10 hours a day in a steady state operation was let to operate for 45 days. The attained conversion of sulfur $\mathrm{X}_{\mathrm{f} 0}$ is measured for fresh catalyst, and then the conversion of sulfur $\mathrm{X}_{\mathrm{fi}}$ is determined every day (run) for the following 45 days. The ratio $\mathrm{X}_{\mathrm{fi}} / \mathrm{X}_{\mathrm{fo}}$ vs. catalyst age is used to express relative activity diminution. The observed values of $\mathrm{X}_{\mathrm{fi}} / \mathrm{X}_{\mathrm{f} 0}$ vs. catalyst age are shown [Table 3, 4].

\section{Results and Discussion}

It can be seen from Table 3, that (CAT-1, $\overline{L p}_{0}=0.059$ $\mathrm{mm}$ ) activity increases very slightly during the first 
100-200 hours and begins to decrease later and drops to about $80 \%$ of the original value after 45 days which means that each $\mathrm{cm}^{3}$ cat. had treated $296.1 \mathrm{~cm}^{3}$ oil.

Table 3. Chemical conversion attained vs. Catalyst age, $\mathrm{ML}_{\text {oil }} / \mathrm{cm}^{3}$ cat.

\begin{tabular}{|c|c|c|c|c|}
\hline $\begin{array}{c}\text { Catalyst age } \\
\mathrm{ML}_{\text {oil }} / \mathrm{cm}^{3} \text { cat. } \\
\text { hours daily })\end{array}$ & $\begin{array}{c}\text { Working } \\
\text { time, } \\
\text { days }\end{array}$ & $\begin{array}{c}\text { Sulfur } \\
\text { content, } \mathrm{S} \\
\mathrm{wt} \%\end{array}$ & $\mathrm{X}_{\mathrm{f}} \%$ & $\begin{array}{c}\text { Relative } \\
\text { activity }= \\
\mathrm{X} / \mathrm{X}_{0}\end{array}$ \\
\hline 6.6 & 1 & 2.35 & 49.46 & 1 \\
\hline 65.8 & 10 & 2.3 & 50.54 & 1.022 \\
\hline 98.7 & 15 & 2.34 & 49.68 & 1.004 \\
\hline 131.6 & 20 & 2.37 & 49.03 & 0.991 \\
\hline 164.5 & 25 & 2.45 & 47.31 & 0.957 \\
\hline 197.3 & 30 & 2.52 & 45.81 & 0.926 \\
\hline 230.2 & 35 & 2.55 & 45.23 & 0.914 \\
\hline 263.2 & 40 & 2.6 & 44.04 & 0.89 \\
\hline 296.1 & 45 & 2.8 & 39.78 & 0.804 \\
\hline
\end{tabular}

Disposed catalyst particles with $\overline{L p}_{0}=059 \mathrm{~mm}$ after 450 hours of operation are washed and extracted with Octane for one hour at $125^{\circ} \mathrm{C}$ to remove soluble constituents, and then the extracted samples were dried at $128^{\circ} \mathrm{C}$ under vacuum of $600 \mathrm{mmHg}$ to remove all the absorbed soluble and other absorbed traces if any. Extraction with Octane cannot scrape and extract light coke deposited in the pore structure of the spent catalyst compared with Benzene which has a higher solubilizing ability to light coke depositions.

The porous structures of the dried and extracted spent catalyst particles are investigated and pore structure properties for pulverized CAT-1 and CAT-2 particles determined are shown in [Table 5]. Drying is followed by a controlled oxidation with air at $380^{\circ} \mathrm{C}$ for 3 hours to assure that the weight of the oxidized sample had reached a constant value. The decrease in the weight of the spent catalyst due to oxidation is calculated and the weight loss

Divided by the weight of the oxidized catalyst is considered as the weight percentage of coke deposited during the 450 hours of operation.

Table 4. Chemical conversion attained vs. Catalyst age, $\mathrm{ML}_{\mathrm{oil}} / \mathrm{cm}^{3}$ cat.

\begin{tabular}{|c|c|c|c|c|}
\hline $\begin{array}{c}\text { Catalyst age } \mathrm{ML}_{\text {oil }} / \mathrm{cm}^{3} \\
\text { cat }(10 \text { hours daily })\end{array}$ & $\begin{array}{c}\text { Working } \\
\text { time, } \\
\text { days }\end{array}$ & $\begin{array}{c}\text { Sulfur } \\
\text { content, } \\
\text { S wt.\% }\end{array}$ & $\mathrm{X}_{\mathrm{f}} \%$ & $\begin{array}{c}\text { Relative } \\
\text { activity } \\
\mathrm{X}_{\mathrm{f}} / \mathrm{X}_{0}\end{array}$ \\
\hline 6.6 & 1 & 2.51 & 46.02 & 1 \\
\hline 65.8 & 10 & 2.46 & 47.11 & 1.024 \\
\hline 98.7 & 15 & 2.46 & 47.12 & 1.024 \\
\hline 131.6 & 20 & 2.46 & 47.03 & 1.02 \\
\hline 164.5 & 25 & 2.55 & 45.12 & 0.98 \\
\hline 197.3 & 30 & 2.54 & 45.41 & 0.986 \\
\hline 230.2 & 35 & 2.56 & 45.05 & 0.979 \\
\hline 263.2 & 40 & 2.65 & 43.04 & 0.9352 \\
\hline 296.1 & 45 & 2.74 & 41.09 & 0.893 \\
\hline
\end{tabular}

The analysis showed that the $\mathrm{S}, \mathrm{C}, \mathrm{H}, \mathrm{N}$ contents of the coke were around $3.96,35.96,1.88,0.49$ wt. \% respectively. The metallic deposits were 0.61 and 0.27 wt. $\%$ for Vanadium and Nickle respectively for
CAT-1 sample, $\overline{L p}_{0}=059 \mathrm{~m}$, while those for CAT- 2 sample $\overline{L p}_{0}=0.059 \mathrm{~mm}$ contained $3.43,28.7,3.61$ and $0.38 \mathrm{wt} . \%$ $\mathrm{S}, \mathrm{C}, \mathrm{H}$ and $\mathrm{N}$ respectively. Vanadium and Nickle contents of the deposits were found to be 0.46 and 0.23 wt. \%. as is shown in Table 6.

The higher levels of deposits noticed for CAT-1 may be attributed to the molecular sieves MS 13X with their active surface converting the high molecular weight molecules

Embedded with $\mathrm{C}, \mathrm{N}, \mathrm{V}$, and $\mathrm{Ni}$ as Asphaltenes and Resins present in heavy oil fractions.

Illustrating these results, each 1 gram of spent CAT-1 loses 0.4097 grams as oxidative coke on burning with air, among those 0.4097 grams $0.0234 \mathrm{~g}$ rams are for sulfur, the Remaining weight of the catalyst i.e. 0.5903 grams are considered as regenerated catalyst( including metallic deposits). Hence the $\mathrm{S}$ wt. $\%,\left\{{ }_{\mathrm{s}}^{\mathrm{g}} / 100 \mathrm{~g}\right.$ reg.cat. $\}$ is equal to $0.0234 \mathrm{~g} \mathrm{~s}_{\mathrm{S}} / 0.5903 \mathrm{~g}$ reg.cat $=3.96 \mathrm{wt} \%$. The pore structure properties of both catalyst types after regeneration are shown in Table 7.

It is seen that the regeneration released most of the lost pore structure properties, [Table 7].

It is noticed that spent catalysts after 450 hours of operation had lost the major portion of their porous structure parameters, while keeping more than $80 \%$ and $89 \%$ of their chemical activity for CAT-1 and CAT-2 respectively [14].

Table 5. Spent catalysts pore structure specifications after 450 hours at $350^{\circ} \mathrm{C}, 50 \mathrm{~atm}$., and LHSV $2.6 \mathrm{~h}^{-1}$

\begin{tabular}{|c|c|c|c|c|}
\hline Cat.symb. & $\begin{array}{c}\text { Fresh } \\
\text { CAT- } 1\end{array}$ & $\begin{array}{c}\text { Spent } \\
\text { CAT- } 1\end{array}$ & $\begin{array}{c}\text { Fresh } \\
\text { CAT- 2 }\end{array}$ & $\begin{array}{c}\text { Spent } \\
\text { CAT-2 }\end{array}$ \\
\hline $\mathrm{Sg}, \mathrm{m}^{2} / \mathrm{g}[\mathrm{BET}]$ & 188 & 85 & 181 & 99 \\
\hline $\mathrm{Sg}, \mathrm{m}^{2} / \mathrm{g}[\mathrm{MP}]$ & 114 & 53 & 111 & 64 \\
\hline $\mathrm{Vp}^{(1)}$ & 0.41 & 0.18 & 0.39 & 0.23 \\
\hline $\mathrm{Vp}^{(2)}$ & 0.32 & 0.14 & 0.34 & 0.17 \\
\hline $\mathrm{dp}^{(1)}$ & 83 & 45 & 87 & 51 \\
\hline $\mathrm{dp}^{(2)}$ & 123 & 75 & 128 & 82 \\
\hline$\rho_{\text {obs.bed, }} / \mathrm{cm}^{3}$ & 0.78 & 0.84 & 0.75 & 0.79 \\
\hline
\end{tabular}

The only explanation for this phenomenon is that coke deposited in the pores of the catalysts during the first stages does not impose the active centers to operate as active sites attracting reactants i.e. electrical charges can move through the deposited coke layer and hence catalyzing reactions. As time is increasing metals deposits destroying the active sites either isolating or poisoning them increase and the coke layer becomes more thick and more solid to a degree that electrical charges cannot be interchanged between reacting molecules and so the covered active centers cannot do their assigned job and thus no catalytic activity is observed.

These solid and thick coke layers start to build up after 200 to 300 hundred hours of operation in conjunction with the metallic deposits destroy progressively the catalytic activity of the active

Centers and then causing activity to decreas 
progressively. Also the degradation of pore structure parameters observed for CAT-1 and CAT-2 justifies the activity loss observed for both catalyst samples with $\overline{L P}_{0}=059 \mathrm{~mm}$, which is found to be 20 and $11 \%$ respectively [14].

The analysis of the porous structure of spent CAT-1 and CAT-2 showed that the most probable diameters of pores had dropped to 45 and 51 ( $\AA$ ) for $\mathrm{dp}^{(1)}$ and to 75 and $82(\AA)$ for $\mathrm{dp}^{(2)}$ for both samples respectively.

Table 6. Composition of deposits on CAT-1 and CAT-2 samples, $\overline{L p}_{0}=059 \mathrm{~mm}, 450$ hours of operation.

\begin{tabular}{|c|c|c|}
\hline Quantity & CAT-1 & CAT-2 \\
\hline $\begin{array}{c}\text { Weight loss due to oxidation/100 g. } \\
\text { spent catalyst sample, \% }\end{array}$ & $\mathbf{4 0 . 9 7}$ & $\mathbf{3 7 . 0 8}$ \\
\hline $\begin{array}{c}\text { Wight of regenerated cat. } \\
\text { Sample, \% }\end{array}$ & $\mathbf{5 9 . 0 3}$ & $\mathbf{6 2 . 9 2}$ \\
\hline $\begin{array}{c}\text { S wt.\%, } \\
\mathrm{g}_{\mathrm{S}} / 100 \mathrm{~g}_{\text {reg.cat }}\end{array}$ & $\mathbf{3 . 9 6}$ & $\mathbf{3 . 4 3}$ \\
\hline $\begin{array}{c}\text { C wt.\%, } \\
\mathrm{g}_{\mathrm{C}} / 100 \mathrm{~g}_{\text {reg.cat }}\end{array}$ & $\mathbf{3 5 . 5 8}$ & $\mathbf{2 8 . 7 0}$ \\
\hline $\begin{array}{c}\text { H wt.\%, } \\
\mathrm{g}_{\mathrm{H}} / 100 \mathrm{~g}_{\text {reg.cat }}\end{array}$ & $\mathbf{1 . 8 8}$ & $\mathbf{3 . 6 1}$ \\
\hline $\begin{array}{c}\text { N wt.\%, } \\
\mathrm{g}_{\mathrm{N}} / 100 \mathrm{~g}_{\text {reg.cat }}\end{array}$ & $\mathbf{0 . 4 9}$ & $\mathbf{0 . 3 8}$ \\
\hline $\begin{array}{c}\text { V wt.\%, } \\
\mathrm{g}_{\mathrm{V}} / 100 \mathrm{~g}_{\text {reg.cat }}\end{array}$ & $\mathbf{0 . 6 1}$ & $\mathbf{0 . 4 6}$ \\
\hline $\begin{array}{c}\text { Ni wt.\%, } \\
\mathrm{g}_{\mathrm{Ni}} / 100 \mathrm{~g}_{\text {reg.cat }}\end{array}$ & $\mathbf{0 . 2 7}$ & $\mathbf{0 . 2 3}$ \\
\hline
\end{tabular}

The micro-pores with diameters less than 20 Angstrom $(\AA)$ were seriously infected and isolated. It is believed that the presence of MS-13X with their acidic surface chemistry support the hydrocracking reaction of the heavy molecules like Asphaltenes, resins, etc. Hydrocracking of these large molecules penetrated into the miso and micro-pores causing these to be plugged and hence, isolated in a manner that they could not be able to catalyze the reactions assigned to. The differential pore size distribution of fresh CAT-1 is shown in Figure 1.

The differential pore size distribution of a spent CAT-1 sample used for 450 hours is shown in Fig.2, where most of the miso-pores with dimeters between 80 and $160(\AA)$ had already disappeared. The major portion of the specific surface area and pore volume were lost, [Table 5].

On regeneration, most of the specific surface area and pore volume of the CAT-1 sample were recovered, Table 7.

The differential pore size distribution of regenerated CAT-1 samples is shown in Fig. 3, with a probable pore diameter around $57(\AA)$.

The pore size distributions for both fresh and spent CAT-2catalysts are shown in Figures 4 and 5.

On regeneration CAT-2 sample recovered $95 \%$ of the $\mathrm{Sg}$ [BET] and $94.4 \%$ of the Sg [MP]. The probable pore diameter recovered $74 \%$ of its original value determined value for fresh sample in the miso-pore size region and $95 \%$ of the original value for probable pore diameter determined for macro pores sizes, [Table 7]. The differential pore size distribution is shown in Fig. 6.

Table 7. Pore structure parameters of regenerated catalysts

\begin{tabular}{|c|c|c|c|c|}
\hline Cat.symb. & $\begin{array}{c}\text { Regenerated } \\
\text { CAT- } 1\end{array}$ & $\begin{array}{c}\% \\
\text { recovery }\end{array}$ & $\begin{array}{c}\text { Regenerated } \\
\text { CAT-2 }\end{array}$ & $\begin{array}{c}\% \\
\text { recovered }\end{array}$ \\
\hline $\begin{array}{c}\mathrm{Sg}, \mathrm{m}^{2} / \mathrm{g} \\
{[\mathrm{BET}]}\end{array}$ & 168 & 89.5 & 171 & 95 \\
\hline $\begin{array}{c}\mathrm{Sg}, \mathrm{m}^{2} / \mathrm{g} \\
{[\mathrm{MP}]}\end{array}$ & 102 & 90.3 & 105 & 94.4 \\
\hline $\mathrm{Vp}^{(1)}$ & 0.37 & 89.5 & 0.37 & 95 \\
\hline $\mathrm{Vp}^{(2)}$ & 031 & 95.3 & 0.32 & 93 \\
\hline $\mathrm{dp}^{(1)}(\boldsymbol{\AA})$ & 57 & 68.7 & 65 & 74 \\
\hline $\mathrm{dp}^{(2)},(\AA)$ & 115 & 93.5 & 122 & 95.3 \\
\hline
\end{tabular}

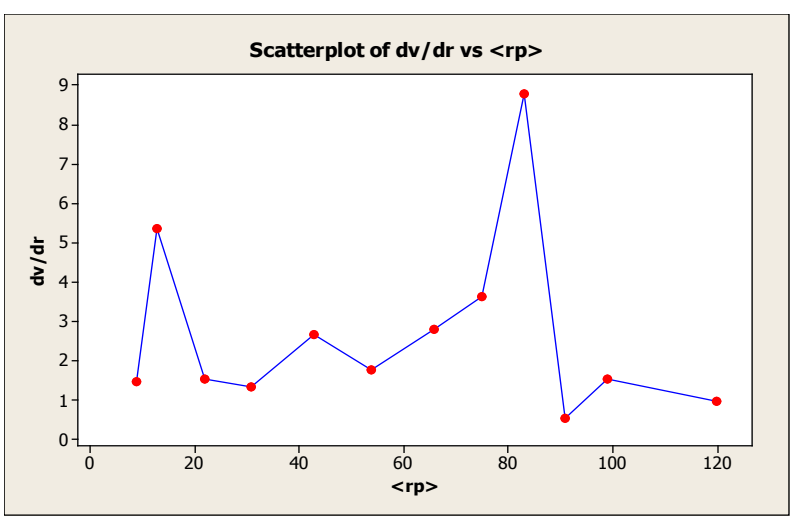

Figure 1. Differential pore size distribution of fresh CAT-1, $\overline{L p}_{0}=0$. $059 \mathrm{~mm}$.

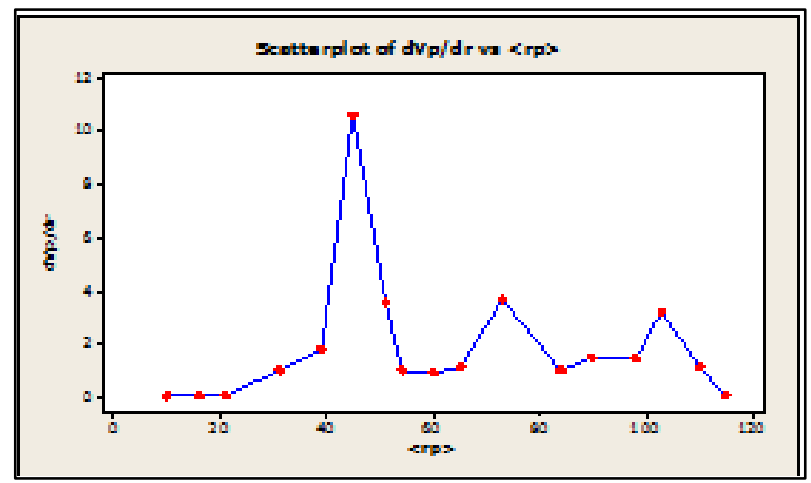

Figure 2. Differential pore size distribution of spent CAT-1, $\overline{L p}_{0}=0$. $059 \mathrm{~mm}$

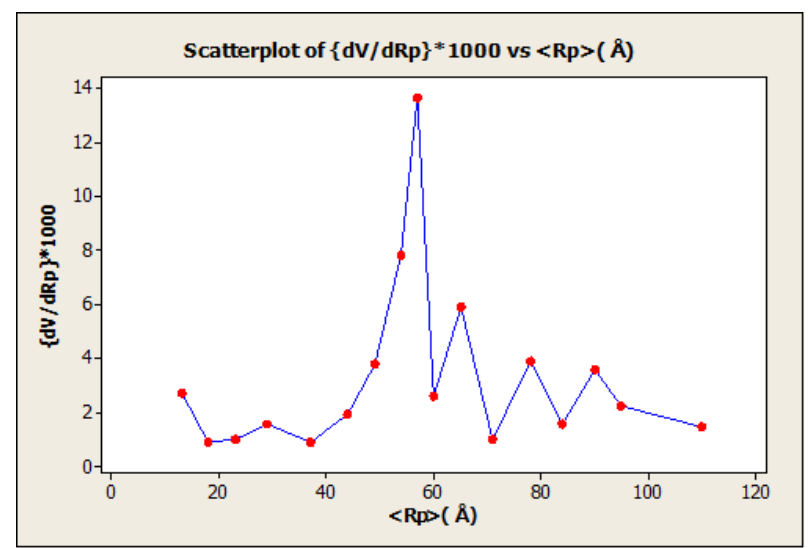

Figure 3. Differential pore size distribution of regenerated CAT-1 sample. 


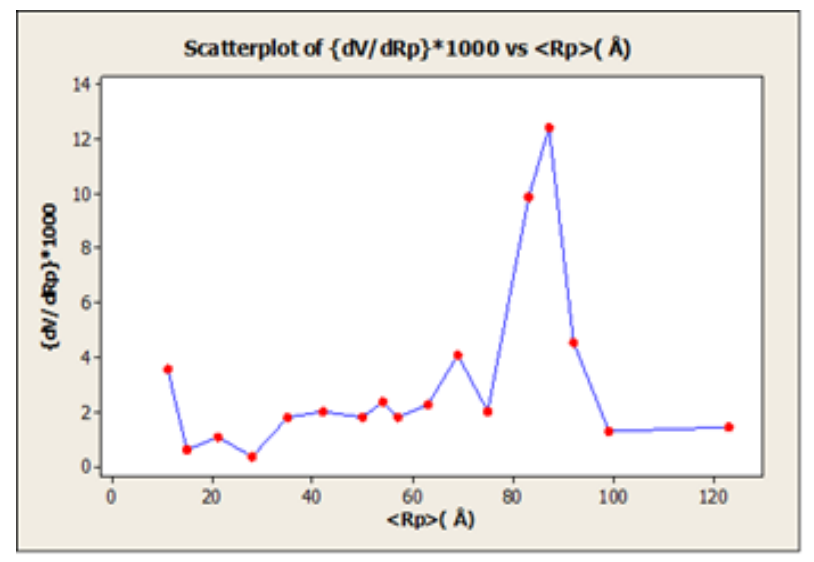

Figure 4. Differential pore size distribution of fresh CAT-2. $\overline{L p}_{0}=0$. $059 \mathrm{~mm}$

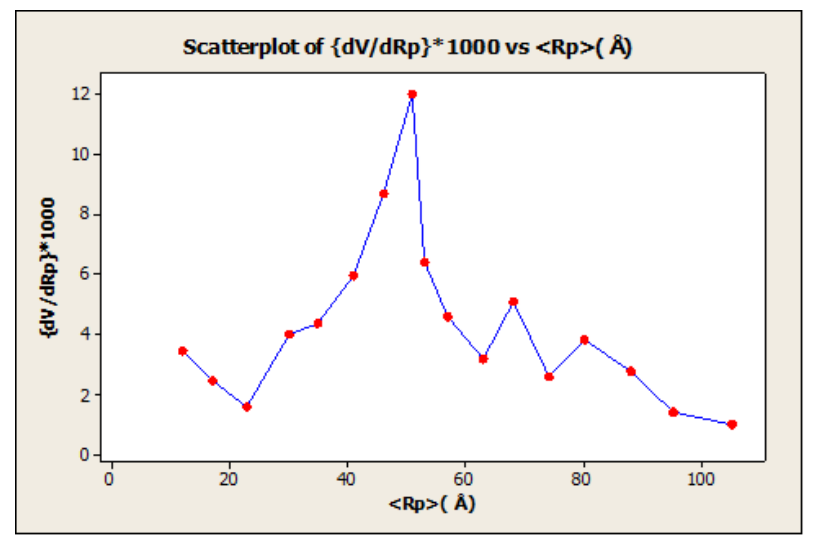

Figure 5. Differential pore size distribution of spent CAT-2. $\overline{L p}_{0}=0$. $059 \mathrm{~mm}$

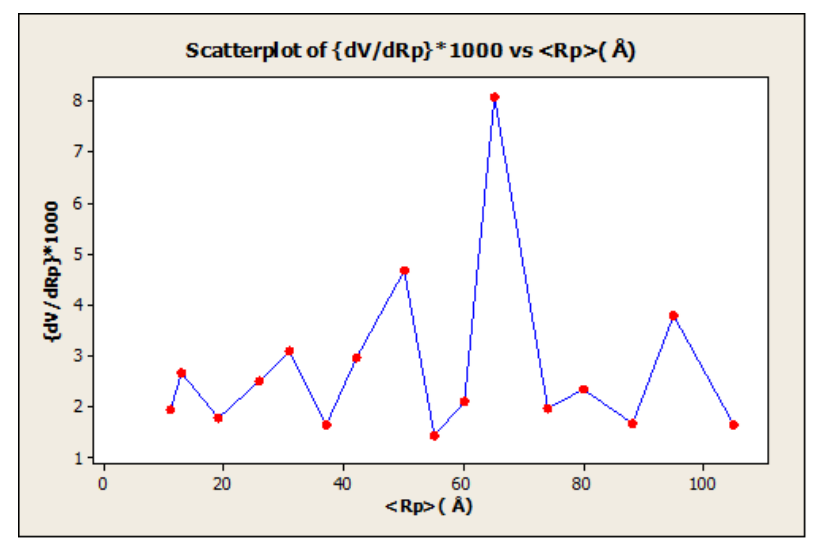

Figure 6. Differential pore size distribution of regenerated CAT-2 sample.

Samples with larger particle having $\overline{L p}_{1}=0.326 \mathrm{~mm}$ showed the results given in Table 8 . The spent catalyst samples showed a higher loss in their pore structure parameters [Tables 8, 9].

It can be seen that the modifications in the pore structure of the cylindrical pellets is more severe than that observed for pulverized ones, where surface areas in the miso-pore and micro pore region had lost more than 60 and $54 \%$ for both CAT-1 and CAT -2 samples, while miso and macro pore surface areas lost were 62.5 and $55.7 \%$ for both types. Pore volumes lost as deduced from Tables 8 and 9 are 56.8 and $52.7 \%$ for the miso-pores and 58.6 and $55 \%$ for the macro pores region for CAT-1 and CAT-2 respectively. These results may give the explanation of the higher catalytic activity drop observed for catalyst CAT-1 impregnated with MS 13X compared to the decrease in activity drop for CAT- 2. All catalyst Samples, having the same particle size $\overline{L p}_{1}=0.326 \mathrm{~mm}$, treated with Hydrogen at $300{ }^{\circ} \mathrm{C}$ and $50 \mathrm{~atm}$. Hydrogen flow rate of $5700 \mathrm{ml} / \mathrm{h}$, (NTP). Sulfided in situ with feedstocks, $\mathrm{C}_{\mathrm{S} 0}=14.63310^{-4}$ $\mathrm{g}-\mathrm{mol} \mathrm{S} / \mathrm{cm}^{3}{ }_{\text {oil }}, \mathrm{API}=9$. These samples were used in a fixed bed reactor $\left(D_{\text {in }} 15 \mathrm{~mm}\right.$, Length $230 \mathrm{~mm}$, bed volume 38 $\mathrm{cm}^{3}$ ) operating with high recycle ratio (complete back-mixing), $\mathrm{LHSV}=2.6 \mathrm{~h}^{-1}, \mathrm{P}=50$ atm., $\mathrm{T}=350^{\circ} \mathrm{C}$, initial sulfur concentration $\mathrm{C}_{\mathrm{S} 0}=14.63310^{-4} \mathrm{~g}-\mathrm{mol} \mathrm{S} / \mathrm{cm}^{3}{ }_{\text {oil, } \mathrm{API}}=9$ and $\overline{L p}_{1}=0.326 \mathrm{~mm}$. [14].

Table 8. Pore structure parameters of fresh catalyst samples. $\overline{\boldsymbol{L p}}_{1}=$ $0.326 \mathrm{~mm}$

\begin{tabular}{|c|c|c|c|c|c|c|}
\hline $\begin{array}{c}\text { Cat. } \\
\text { Sample, } \\
\overline{L p}_{1}= \\
0.326 \\
\mathrm{~mm}\end{array}$ & $\begin{array}{c}\mathrm{Sg} \\
{[\mathrm{BET}],} \\
\mathrm{m}^{2} / \mathrm{g}\end{array}$ & $\begin{array}{c}\mathrm{Sg} \\
{[\mathrm{MP}],} \\
\mathrm{m}^{2} / \mathrm{g}\end{array}$ & $\begin{array}{c}\mathrm{Vp}^{(1)} \\
\mathrm{cm}^{3} / \mathrm{g}\end{array}$ & $\begin{array}{c}\mathrm{Vp}^{(2} \\
\left.\mathrm{cm}^{3} / \mathrm{g}\right)\end{array}$ & $\begin{array}{c}\mathrm{dp}^{(1)} \\
(\AA)\end{array}$ & $\begin{array}{c}\mathrm{dp}^{(2)} \\
(\AA)\end{array}$ \\
\hline CAT-1 & 189.4 & 115.8 & 0.406 & 0.29 & 77 & 118 \\
\hline CAT-2 & 181.3 & 111.5 & .402 & 0.30 & 81 & 122 \\
\hline
\end{tabular}

Table 9. Pore structure parameters of spent catalyst samples. $\overline{L p}_{1}=$ $0.326 \mathrm{~mm}, 450$ hours of operation.

\begin{tabular}{|c|c|c|c|c|c|c|}
\hline $\begin{array}{c}\text { Cat. Sample, } \\
\begin{array}{c}\mathrm{Lp} \\
1\end{array}=0.326 \\
\mathrm{~mm}\end{array}$ & $\begin{array}{c}\mathrm{Sg} \\
{[\mathrm{BET}],} \\
\mathrm{m}^{2} / \mathrm{g}\end{array}$ & $\begin{array}{c}\mathrm{Sg} \\
{[\mathrm{MP}],} \\
\mathrm{m}^{2} / \mathrm{g}\end{array}$ & $\begin{array}{c}\mathrm{Vp}^{(1)} \\
\mathrm{cm}^{3} / \mathrm{g}\end{array}$ & $\begin{array}{c}\mathrm{Vp}^{(2} \\
\left.\mathrm{cm}^{3} / \mathrm{g}\right)\end{array}$ & $\begin{array}{c}\mathrm{dp}^{(1)} \\
(\AA)\end{array}$ & $\begin{array}{c}\mathrm{dp}^{(2)} \\
(\AA)\end{array}$ \\
\hline CAT-1 & 75 & 44 & 0.18 & 0.12 & 38 & 69 \\
\hline CAT-2 & 83 & 49 & 0.19 & 0.13 & 44 & 73 \\
\hline
\end{tabular}

The degradation of catalyst activity is measured for both catalyst samples particles by measuring the attained chemical conversion versus catalyst age. The experimental results are shown in Table 10 and Table 11 for CAT-1 and CAT-2 respectively. The graphical presentations are shown in shown in Figures 7 and 8.respectively.

The CAT-1 activity data showed that the effectiveness factor $\eta_{0}=0.940$ for $\overline{L p}_{0}=0.059 \mathrm{~mm}$ and $\eta_{1}=0.452$ for $\overline{L p} 1=$ $0.326 \mathrm{~mm}$. [14].

The decrease in the activity started early during the initial hours of operation and continued progressively with increasing time, these results showed that during the 450 hours of operation the catalyst had lost $55.41 \%$ of its activity. The value of $20 \%$ activity loss calculated for the pulverized particles [14] for the same period of operation, when compared to the $55.41 \%$ determined for the

Cylindrical particles, $\overline{L p}_{1}=0.326 \mathrm{~mm}$, can be attributed to the deposition of coke and metals, a phenomenon which is accelerated by the presence of molecular sieves with their acidic surface supporting the hydro cracking reaction in the outer surface of particles isolating the central and major part of the particle from contributing in the reactions involved. 


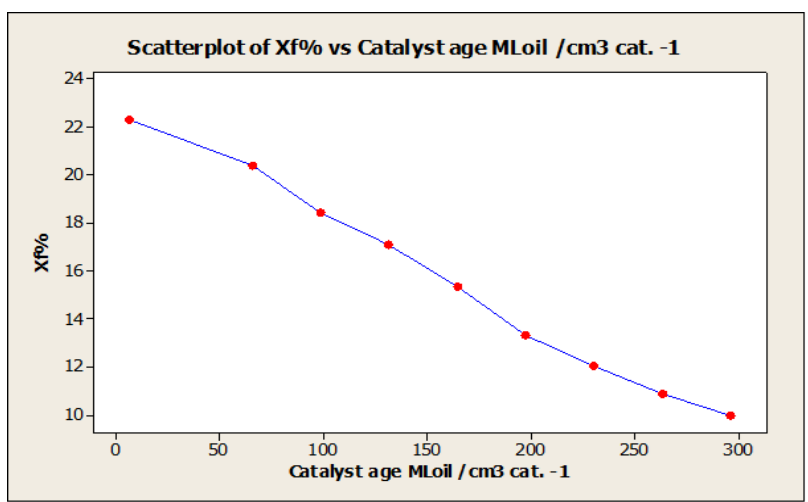

Figure 7. CAT-1 activity expressed as chemical conversion of sulfur compounds vs. catalyst operating time, $\mathrm{ML}$ oil $/ \mathrm{cm}^{3}$ catalyst, $\overline{L p}_{1}=0.326 \mathrm{~mm}$.

Table 10. Chemical conversion attained vs. Catalyst age, $\mathrm{ML}_{\text {oil }} / \mathrm{cm}^{3}$ cat., CAT-1 sample. $\overline{L p}_{1}=0.326 \mathrm{~mm}$

\begin{tabular}{|c|c|c|c|}
\hline $\begin{array}{c}\text { Catalyst age } \mathrm{ML}_{\text {oil }} \\
/ \mathrm{cm}^{3} \text { cat. }(10 \text { hours } \\
\text { daily) }\end{array}$ & $\begin{array}{c}\text { Working } \\
\text { time, days }\end{array}$ & $\begin{array}{c}\text { Sulfur content, } \\
\mathrm{S} \text { wt.\% }\end{array}$ & $\mathrm{X}_{\mathrm{f}} \%$ \\
\hline 6.6 & 1 & 3.611 & 22.340 \\
\hline 65.8 & 10 & 3.70 & 20.418 \\
\hline 98.7 & 15 & 3.79 & 18.430 \\
\hline 131.6 & 20 & 3.85 & 17.130 \\
\hline 164.5 & 25 & 3.94 & 15.360 \\
\hline 197.3 & 30 & 4.03 & 13.340 \\
\hline 230.2 & 35 & 4.09 & 12.020 \\
\hline 263.2 & 40 & 4.14 & 10.890 \\
\hline 296.1 & 45 & 4.187 & 9.960 \\
\hline
\end{tabular}

The activity of CAT-2 sample was investigated at the same operating conditions applied for CAT-1 sample; the results are shown in Table 11 and presented in Fig. 8. The investigation showed that the effects of intra-pellet mass transfer limitations were less severe than those observed for CAT-1 sample.

Table 11. Chemical conversion attained vs. Catalyst age, $\mathrm{ML}_{\text {oil }} / \mathrm{cm}^{3}$ cat CAT-2 sample. $\overline{L p}_{1}=0.326 \mathrm{~mm}$.

\begin{tabular}{|c|c|c|c|}
\hline $\begin{array}{c}\text { Catalyst age MLoil } \\
/ \mathrm{cm}^{3} \text { cat }(10 \text { hours } \\
\text { daily) }\end{array}$ & $\begin{array}{c}\text { Working time, } \\
\text { days }\end{array}$ & $\begin{array}{c}\text { Sulfur content, } \\
\text { S wt.\% }\end{array}$ & $\mathrm{X}_{\mathrm{f}} \%$ \\
\hline 6.6 & 1 & 3.63 & 22.04 \\
\hline 65.8 & 10 & 3.68 & 20.78 \\
\hline 98.7 & 15 & 3.77 & 18.85 \\
\hline 131.6 & 20 & 3.83 & 17.48 \\
\hline 164.5 & 25 & 3.90 & 16.09 \\
\hline 197.3 & 30 & 3.98 & 14.37 \\
\hline 230.2 & 35 & 4.04 & 12.93 \\
\hline 263.2 & 40 & 4.11 & 11.52 \\
\hline 296.1 & 45 & 4.15 & 10.86 \\
\hline
\end{tabular}

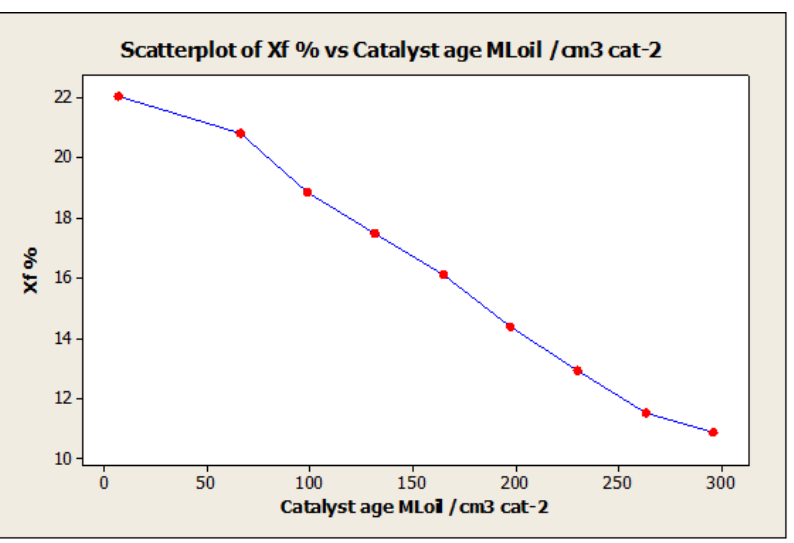

Figure 8. CAT-2 activity expressed as chemical conversion of sulfur compounds vs. catalyst operating time, $\mathrm{ML}$ oil $/ \mathrm{cm} 3$ catalyst, $\overline{L p}_{1}=0.326$ $\mathrm{mm}$

The pore structure of CAT-2 sample which is embedded with more pore sizes in the miso- and macro-pores gave it more resistant to the harmful effects of deposits and gave CAT-2 a higher effectiveness factor, $\eta 0=0.965$ for $\overline{L p}_{0}=0$. $059 \mathrm{~mm}$ and $\eta_{1}=0.479$ for $\overline{L p}_{1}=0.326 \mathrm{~mm}$.

The results of the analysis of deposited materials on both catalysts are shown in table 12 .

Table 12. Deposits composition on catalyst cylindrical extrudates.

\begin{tabular}{|c|c|c|c|c|}
\hline $\begin{array}{c}\text { Catalyst samples, } \\
\overline{L p}_{1}=0.326 \mathrm{~mm}\end{array}$ & Coke wt.\% ${ }^{\#}$ & $\begin{array}{c}\mathrm{V}^{*} \\
\text { Wt.\% }\end{array}$ & $\begin{array}{c}\mathrm{Ni}^{* *} \\
\text { Wt.\% }\end{array}$ & $\begin{array}{c}\text { Reg.cat. } \\
{ }_{* * *} \\
\text { Wt.\% }\end{array}$ \\
\hline CAT-1 & 30.06 & 0.402 & 0.177 & 69.94 \\
\hline CAT -2 & 32.65 & 0.382 & 0.169 & 67.35 \\
\hline
\end{tabular}

\#: Weight loss due to oxidation/100 g. spent catalyst sample, *: V wt. \%, $\mathrm{g}_{\mathrm{V}} / 100 \mathrm{~g}_{\text {reg.cat, } * *}$ Ni wt. $\%, \mathrm{~g}_{\mathrm{Ni}} / 100 \mathrm{~g}_{\text {reg.cat, } * * * \text { w weight of regenerated }}$ catalyst sample/100 g of spent catalyst sample.

On regeneration, both catalysts recovered most of their pore structure parameters. The results are illustrated in Table 13

Table 13. Pore structure parameters of regenerated catalyst samples.

\begin{tabular}{|c|c|c|}
\hline Catalyst & CAT -1 & CAT-2 \\
\hline $\begin{array}{c}\mathrm{Sg}[\mathrm{BET}], \\
\mathrm{m}^{2} / \mathrm{g}\end{array}$ & 166.76 & 163.27 \\
\hline $\begin{array}{c}\mathrm{Sg}[\mathrm{MP}], \\
\mathrm{m}^{2} / \mathrm{g}\end{array}$ & 94.96 & 99.54 \\
\hline $\begin{array}{c}\mathrm{Vp}^{(1)} \\
\mathrm{cm}^{3} / \mathrm{g}\end{array}$ & 0.33 & 0.34 \\
\hline $\begin{array}{c}\mathrm{Vp}^{(2} \\
\left.\mathrm{cm}^{3} / \mathrm{g}\right)\end{array}$ & 0.21 & 0.24 \\
\hline $\begin{array}{c}\mathrm{dp}^{(1)} \\
(\AA)\end{array}$ & 54 & 61 \\
\hline $\begin{array}{c}\mathrm{dp}^{(2)} \\
(\AA)\end{array}$ & 96 & 107 \\
\hline
\end{tabular}


It is clearly noticed that by oxidation of spent catalyst samples the recovery of the specific surface area misoand micro- pores approached $90 \%$, while the level of recovery in macro and miso-pores was between 80 and $89 \%$. The most probable pore diameter recovered 70 to $75 \%$ of that value measured for fresh samples.

\section{Conclusions}

The tested catalyst samples lost the major portion of their specific surface area and pore volume on operation .The analyzed deposits contained C, S, N, H, V and $\mathrm{Ni}$. The pulverized samples with $\overline{L p}_{0}=0.059 \mathrm{~mm}$, maintained more than $80 \%$ of their activity in spite that more than $60 \%$ of their pore surface area and pore volume. CAT-2 with more miso and macro-pores showed to be more resistant to deposits than the CAT-1 embedded with molecular sieves MS $13 \mathrm{X}$ and with more pores in the micro and miso-pores region.

Coke deposited is of changing nature and chemistry. Activity curves and the literature on coke deposition phenomena, support that coke formed in the early stages do not impose active sites from contribution in the catalysis of the reaction assigned to. While as time is increased the coke changes chemistry and nature and begins to hinder the contribution of the active sites side by side with the metallic deposits mainly $\mathrm{V}$ and $\mathrm{Ni}$. The larger catalyst particles with $\overline{L p}_{1}=0.326 \mathrm{~mm}$ showed a higher rate of catalyst deactivation, where activity diminution curves showed higher deactivation rates compared with the smaller pulverized ones.

Intra-particle mass transfer limitations were obvious and their effects were clear and influential especially for the particles with $\overline{L p}_{1}=0.326 \mathrm{~mm}$, where $\eta$ was 0.452 and 0.479 for CAT-1 and CAT-2 respectively. The amounts deposited support that the external part of the particles was exposed to the metallic and coke deposits.

Finally on regeneration the major portion of pore structure parameters were recovered and a small portion remained unrecovered.

\section{REFERENCES}

[1] N. Hirotsugu, S. Yasuo, O. J. Yutaska, Hydrodesulphurizat ion Reactions of Residual Oils (Part 3), Effects of Various Factors on Catalyst Life Jap.Petrol. Ins., 23(5), 321-327, 1980.
[2] Dduha Chehadeh, Hamza Albazzaz* and Dawoud Bahzad, Predicted Effects of Heavy Feeds on the Deactivation of a Commercial Atmospheric Residue Desulfurization Catalyst System, Energy \& Fuels, 32 (4), 5480-5488, 2018.

[3] J.Ammus, Ph.D. Thesis, National Technical University of Athens, Greece, 1985.

[4] Kazuo Idei, Takeshige Takahashi, Takami Kai, Effect of Coke and Metal Deposition on Catalyst Deactivation at Early Stages of Resid Hydrodesulfurization Operation, Journal of the Japan Petroleum Institute 45(5): 295304. September 2002.

[5] Hong Nie, Huifeng Li, Qinghe Yang, Dadong Li, Effect of structure and stability of active phase on catalytic Performance of hydro treating catalysts, Catalysis Today, May 2018.

[6] J. M. Ammus, G. P. Androutsopolous, An investigation of the deactivation phenomena associated with the use of Commercial HDS catalysts, Ind. Eng. Che. Res.26, 1312-1323, 1987.

[7] E. Furimsky, Catalytic removal of sulfur, nitrogen, and Oxygen from heavy gas oil, AICHE J., 25(2), 306-311, 1979.

[8] E. Furimsky, Determination of Coke on Catalyst Surface Ind. Eng. chem. prods. Res. Dev., 18(3)206.1979.

[9] Butt, J.B., Petersen, E.E., Activation, Deactivation, and Poisoning of Catalysts, Academic Press: San Diego, CA, USA, 1988.

[10] T. Ohutsuka, Catalyst for hydrodesulphurization of Petroleum residua Cat. Rev. Sci. Eng., 16(2), 291-325, 1977.

[11] J. M. Pazos, J. C Gonzales and A. J. Salazar, Effect of catalyst properties and operating conditions on Hydro processing of high-metals feeds, Ind. Eng. Chem. Process Des. Dev., 22(4), 653, 1983.

[12] Kazuo Idei, Takeshige Takahashi, Takami Kai," Estimation of Coke and Metal Deposition Distribution within Hydrodesulphurization Catalyst Pore at the Last Stage of Operation. Journal of the Japan Petroleum Institute 46(1):45-52 January 2003.

[13] V. H. J. de Beer, M. J. M. Van Der Aalst, C. J. Machiels, and G. C. A. Schuit, The $\mathrm{CoO}-\mathrm{MoO} 3 / \gamma$-AL2O3 catalyst: VII. Influence of the Support, Journal of Catalysis, 43, 78-89 (1976).

[14] J. M. Amous., Chemical and Materials Engineering Journal, Vol. 6 No.1, 2018. 